\title{
The Comparison of the Effects of Estrogen and Melatonin against Corneal Disorders in Ovariectomized and Pinealectomized Rats
}

\author{
Elif Taslidere (Corresponding author) \\ Department of Histology and Embryology, \\ Faculty of Medicine, Inonu University, Malatya, Turkey \\ E-mail: eliftaslidere@hotmail.com \\ ORCID ID: 0000-0003-1723-2556 \\ Nigar Vardi \\ Department of Histology and Embryology, \\ Faculty of Medicine, Inonu University, Malatya, Turkey \\ Seda Tasdemir \\ Department of Pharmacology, \\ Faculty of Medicine Inonu University, Malatya, Turkey \\ Azibe Yildiz \\ Department of Histology and Embryology, \\ Faculty of Medicine, Inonu University, Malatya, Turkey
}

\begin{abstract}
The aim of the current study was to evaluate the role of estrogen (E) and melatonin (M) in preventing corneal disorders in ovariectomized $(\mathrm{Ovx})$ and pinealectomized $(\mathrm{Px})$ rats. Rats were randomly grouped into seven as follows: Sham-operated, Px, Bilateral Ovx, Ovx $+\mathrm{Px}, \mathrm{Ovx}+\mathrm{Px}+\mathrm{M}$, Ovx $+\mathrm{Px}+\mathrm{E}$, $\mathrm{Ovx}+\mathrm{Px}+\mathrm{EM}$. Rats with Px, Ovx or Ovx+Px were housed for 5 months before the beginning of treatment. Melatonin-treated animals were injected with $5 \mathrm{mg} / \mathrm{kg}$ melatonin for 28 days. Estro-gentreated animals received subcutaneous injections of $250 \mu \mathrm{g} / \mathrm{kg} \beta$-estradiol17-cypionate once a week for 4 weeks. At the end of the study eyes tissues were fixed in 10\% formol and was embedded in paraffin. Sections of tissue were cut at $5 \mu \mathrm{m}$, mounted on slides, stained with hematoxylin-eosin. The mean thicknesses of the total cornea, corneal epithelium, stroma and descement membrane from three different areas of each cornea were measured. Pinealectomy and ovariectomy caused an increase in the thickness of the epithelium, stroma, descement membrane and total cornea. The corneal thicknesses was higher in Ovx group than Px group. Making of ovariectomy and pinealectomy together didn't more affect the corneal thicknesses according to the individual. In conclusions, estrogen administration was more effective than melatonin in respect to preservation of corneal structures.
\end{abstract}

Keywords: Ovariectomy, Pinealectomy, Cornea, Estrogen, Melatonin

\section{Special Issue of Health Sciences}

DOI: $10.7176 / \mathrm{JSTR} / 7-08-03$

\section{Introduction}

The cornea is the outermost avascular and transparent part of the eye consisting of epithelium, Bowman's layer, stroma, Descemet's membrane, and endothelium (Mittanamalli et al., 2018 Sridhar et $a l$. , 2018) Each layer has a specific important function, and a defect in any of these layers can lead to corneal disorders.

Women experience instabilities in sex steroids hormonal changes throughout their life span in association with puberty, ovarian cycles, pregnancy, and aged menopause (Giuffré et al., 2007) 
Estrogens are steroid hormones long known for their profound effects on both male and female reproductive systems. Estrogens regulate growth, differentiation, and function of diverse tissues both within and outside the reproductive system. The effects of estrogens are mediated by specific nuclear receptors, the estrogen receptor $\alpha$ and $\beta$ types, that act as hormone-inducible transcription factors (Kumar et al., 87, Evans et al., 88, King et al., 94). The receptors for estrogen were found in the nuclei of corneal epithelial, stroma and endothelial cell thereby suggesting that these tissues may well be target sites for hormonal influences (Wickham et al., 20006, Suzuki et al., 2001, Tachibana et al., 2000).

Melatonin (MT) is chemically known as $N$-Acetyl-5-methoxytryptamine which, is a hormone produced mainly by the pineal gland from the amino acid precursor, L-tryptophan. It plays a major role in regulating the internal clock that sets daily events and in controlling diverse physiological functions, such as regulation of the circadian rhythm of sleep and waking (Reiter et al., 91), anti-inflammatory actions (Esposito et al., 2010), anticancer effects (Mediavilla et al., 2010), antioxidant activity (Reiter et al., 2014), and reduction of intraocular pressure (IOP) (Samples et al., 88). There are three membrane MT receptor subtypes (MT1, MT2, and MT3) in the ocular tissues comprising the retina, ciliary body, lens, lachrymal glands, and cornea (Wiechmann et al., 2009).

The aim of the present study was to evaluate the effects of estrogen and melatonin therapy on corneal disorders in ovariectomized (Ovx) and pinealectomized (Px) rats.

\section{Materials and Methods \\ Experimental groups}

Fifty-six female Wistar rats weighing 150-200 g were kept at a constant temperature $\left(21 \pm 2{ }^{\circ} \mathrm{C}\right)$ and humidity $(60 \pm 5 \%)$ in a controlled room in which a $12: 12 \mathrm{~h}$ light-dark cycle was maintained. The rats were divided into seven groups of eight animals each by simple randomization methods as follows: 1) Sham-operated 2) Px 3) Bilateral Ovx 4) Ovx+Px 5) Ovx+Px+Melatonin (M) 6) Ovx+Px+estrogen (E) 7) Ovx+Px+EM. Rats with Px, Ovx or Ovx+Px were housed for 5 months before the beginning of treatment. Melatonin (Sigma Chemical Co., St Louis, MO, USA) was dissolved in ethanol and further diluted in saline (vehicle) $(0.09 \% \mathrm{NaCl}, \mathrm{w} / \mathrm{v})$ to give a fi nal concentration of $1 \%$. Melatonin-treated animals were injected with $5 \mathrm{mg} / \mathrm{kg}$ melatonin (i.p.) for 28 days. All injections were administered at 17:00 h. Estro gen-treated animals received subcutaneous injections of $250 \mu \mathrm{g} / \mathrm{kg} \beta$-estradiol

17-cypionate (Sigma) in corn oil once a week for 4 weeks. Animals from sham-operated and Ovx $+\mathrm{Px}$ group received an equal volume $(0.5 \mathrm{~mL} / \mathrm{kg})$ of vehicle solution. The experiment was performed in accordance with the Guidelines for Animal Research from the National Institute of Health and was approved by the Committee on Animal Research at Inonu University, Malatya. For experimental Px and Ovx in the same season, the rats were preoperatively anesthetized with a mixture of ketamine hydrochloride $(75 \mathrm{mg} / \mathrm{kg})$ and xylazine hydrochloride $(8 \mathrm{mg} / \mathrm{kg})$ intraperitoneally (i.p.). According to anatomic localization of pineal gland and ovaries, the skin was shaved with electric clippers and prepared with povidone-iodine (Poviiodeks; Kim-Pa Ilac Lab. Tic. Ltd. Sti., Istanbul, Turkey). During the surgical procedure asepsis was maintained with a local sterile environment.

\section{Pinealectomy}

Pinealectomy was performed as described by Hoffman and Reiter (Hoffman et al., 65). The skin on the top of the head was cut to expose the skull. The animal was fastened to the dissection table; an incision was made in the skin and the subcutaneous tissue, bringing the lambda into view. The skullcap was opened with the aid of a micromotor, bringing the cerebral hemispheres and the superior sagittal sinus into view. The pineal gland, located under the venous sinus, was removed in one piece using forceps. Next, the bone fragment was returned to its place and the surgical layers were sutured. After surgery, the animals received a single dose of prophylactic antibiotic. The procedure was completed within 15 min. Pinealectomy was confirmed by the histological evaluation of the gland for each animal. Rats in the sham-operated group underwent similar surgical procedures without the removal of the pineal gland.

\section{Ovariectomy}

It was performed bilateraly under the anesthesia $4 \mathrm{~cm}$ midline laparotomy was made through the flank skin of the rat, and the ovaries and ovarian fat were removed. Ovaries were isolated

by ligation of the most proximal portion of the oviduct before removal (Waynfort et al., 92). Immediately after surgery, $5 \mathrm{mg} / \mathrm{kg}$ of carprofen was injected subcutaneously for analgesia. 


\section{Histolopathologic Examination}

At the end of the study eyes tissues were fixed in $10 \%$ formol and was embedded in paraffin. Sections of tissue were cut at $5 \mu \mathrm{m}$, mounted on slides, stained with hematoxylin-eosin (H-E).

\section{Semiquantitative Evaluation}

The mean thicknesses of the total cornea, corneal epithelium, stroma and descement membrane from three different areas of each cornea were measured using a Leica Q Win Plus Image Analysis System (Leica Micros Imaging Solutions Ltd, Cambridge, United Kingdom) at 40X.

\section{Results}

The stratified squamous epithelium, stroma and descement membrane were normal histologic appearance in the sham group. A thin layer of simple squamous endothelium was observed under the descement membrane (Figures 1). The mean thicknesses for the sham group were as follows: epithelium, 87,85 $\pm 16,9 \mu \mathrm{m}$; stroma, 280,21 $\pm 68,4 \mu \mathrm{m}$; descement membrane, $21,53 \pm 4,67 \mu \mathrm{m}$ and total cornea, $397,93 \pm 79,3 \mu \mathrm{m}$. Pinealectomy and ovariectomy caused an increase in the thickness of the epithelium, stroma, descement membrane and total cornea. The corneal thicknesses was higher in Ovx group than Px group.

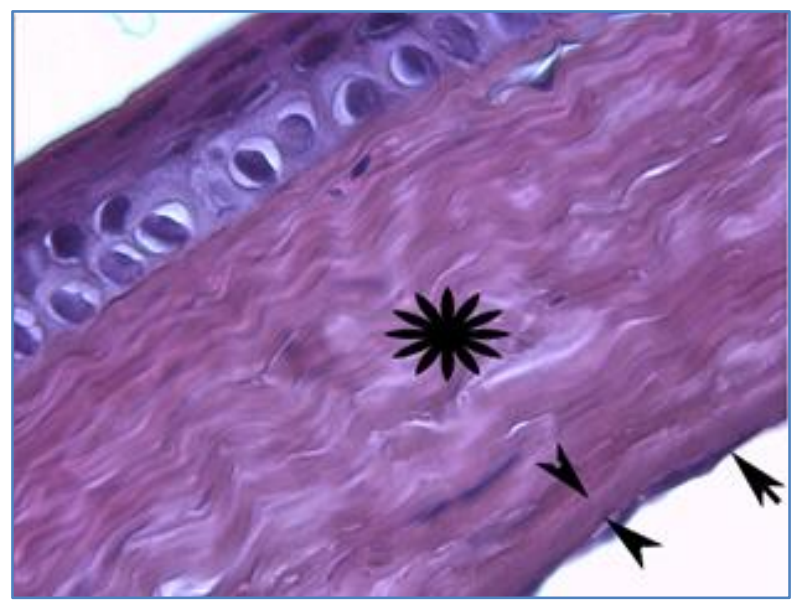

Figure 1: Sham group; the stroma (star), descement membrane (between two arrow heads) and endothelium (arrow) appear normal. H-E X100

The mean thicknesses for the Px and Ovx groups were as follows: epithelium, 99,58 $\pm 29,7$ and 144,55 $\pm 17,2 \mu \mathrm{m}$; stroma, 319,69 \pm 64,7 and 396,69 $\pm 83,9 \mu \mathrm{m}$; descement mebrane 24,05 \pm 7,26 and 24,89 \pm $2,62 \mu \mathrm{m}$; total cornea, 439,16 $\pm 101,6$ and 562,79 $\pm 97,6 \mu \mathrm{m}$ (respectively). Making of ovariectomy and pinealectomy together didn't more affect the corneal thicknesses according to the individual. The mean thicknesses for the Ovx+Px group are as follows: epithelium, 100,12 $\pm 15,5 \mu \mathrm{m}$; stroma, 393,61 $\pm 40,2 \mu \mathrm{m}$; descement membrane 26,97 $\pm 4,33 \mu \mathrm{m}$, total cornea $\mu \mathrm{m}, 521,91 \pm 45,2 \mu \mathrm{m}$. In Px, Ovx and Px+Ovx groups, the stroma was highly edematous. Wide detachment in the stroma were observed (Figures 2A, B and C).
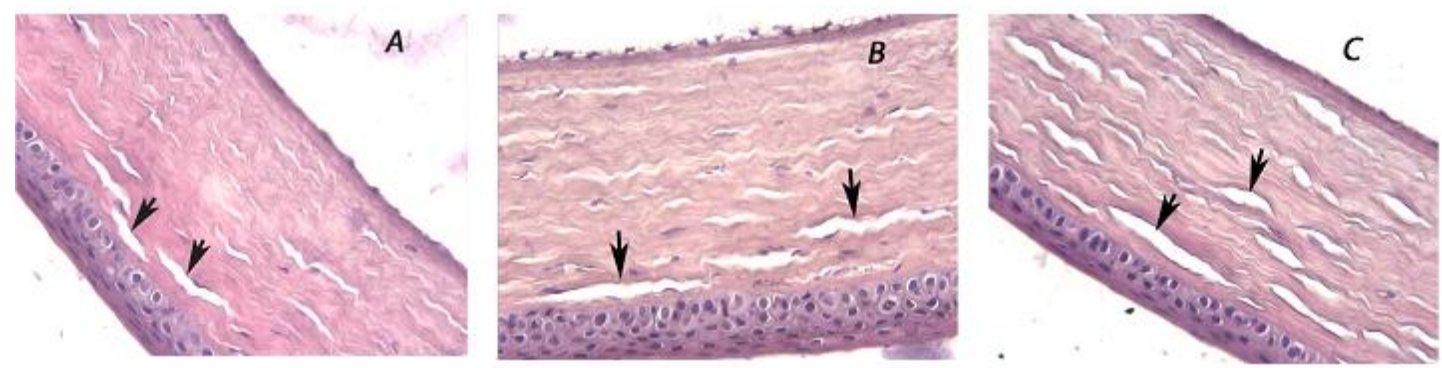

Figure 2: Px (A), Ovx (B) and Ovx+Px (C) groups; stromal detachment is prominent (arrows). H-EX40. 
In addition, the lining of endothelial cells and shapes were destroyed in this groups. Also, vacuolization was seen in the cytoplasma of endothelium cells. The border of descement membrane distruption was detected especially in Ovx and Ovx+Px groups (Figures 3A, B and C).
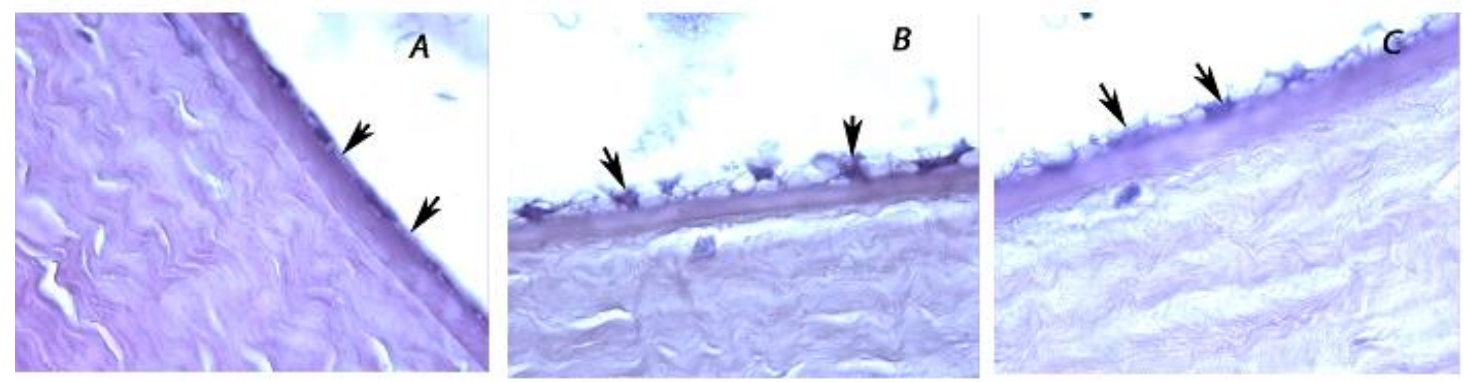

Figure 3: Px (A) group; vacuolisation (arrows), Ovx (B) and Ovx+Px (C); distribution of shape in endothelium (arrows). H-EX100.

The most obvious improvement among the treatment groups occurred in the Ovx+Px+E group (epithelium, 84,48 $\pm 19,7 \mu \mathrm{m}$; stroma, 343,74 $\pm 62,4 \mu \mathrm{m}$; descement membrane 19,01 $\pm 2,48 \mu \mathrm{m}$, total cornea $\mu \mathrm{m}, 455,62 \pm 56,1 \mu \mathrm{m}$ ) followed by the Ovx+Px+EM (epithelium, 87,89 $\pm 20,6 \mu \mathrm{m}$; stroma, $385,96 \pm 46,0 \mu \mathrm{m}$; descement membrane 21,88 $\pm 2,1 \mu \mathrm{m}$, total cornea $\mu \mathrm{m}, 513,68 \pm 54,9 \mu \mathrm{m})$ and Ovx + Px + M (epithelium, 109,77 $\pm 12,4 \mu \mathrm{m}$; stroma, 468,23 $\pm 35,0 \mu \mathrm{m}$; descement membrane 24,13 \pm $4,80 \mu \mathrm{m}$, total cornea $\mu \mathrm{m}, 598,94 \pm 42,9 \mu \mathrm{m}$ ) groups (Figures 4A, B and C).
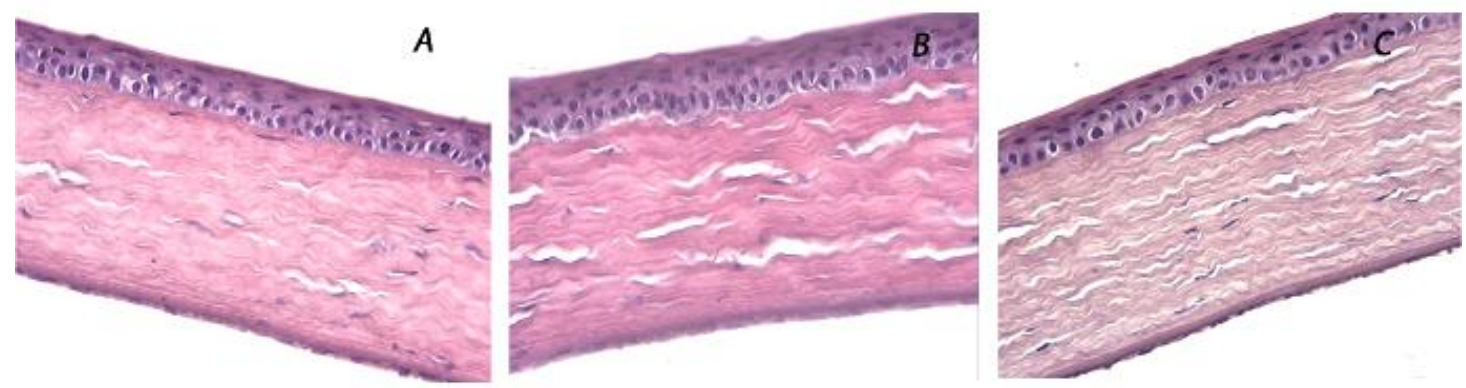

Figure 4: Ovx+Px+E(A), Ovx+Px+EM (B) and Ovx+Px+M (C) groups; the histological appereance of corneal structures. H-EX40.

Estrogens administration was more effective than melatonin in respect to preservation of corneal structures. Stroma detachment was not extensive in the estrogens-administered groups. Moreover, the layer of corneal endothelium was almost intact and more arranged except slight vacuolisation in the $\mathrm{Ovx}+\mathrm{Px}+\mathrm{E}$ and $\mathrm{Ovx}+\mathrm{Px}+\mathrm{EM}$ groups (Figures $5 \mathrm{~B}$ and $6 \mathrm{~B}$ ). On the other hand, degenerative changes were still present in endothelium such as rupture between cells and desquamation in the Ovx $+\mathrm{Px}+\mathrm{M}$ group (Figure 5C). The mean thicknesses of the corneal epithelium, stroma, descement membran and total cornea were statistically significantly different between the groups as shown in Table $\underline{\mathrm{I}}$.
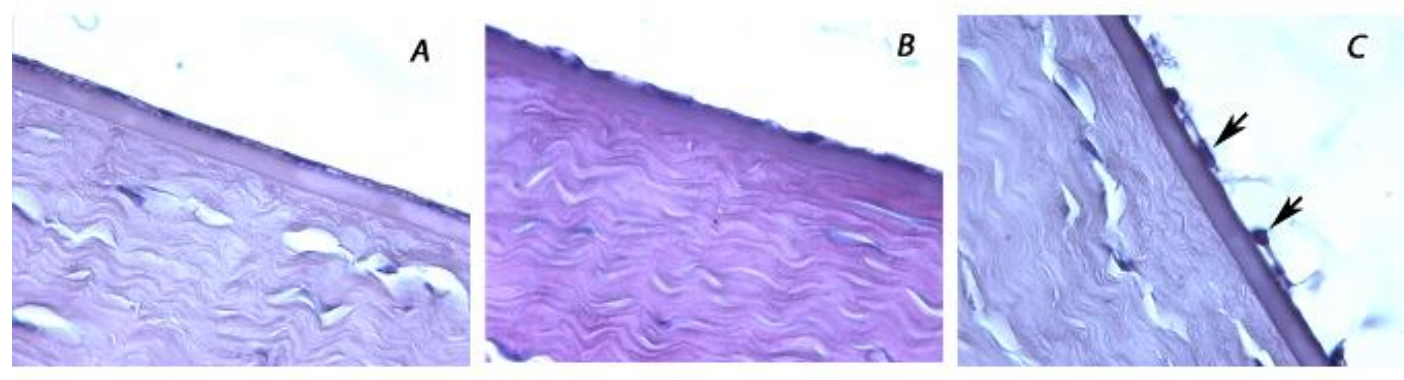

Figure 5: Ovx+Px+E(A), Ovx+Px+EM (B) groups; endothelial cells show almost normal histological structures except slight vacuolization, $\mathbf{O v x}+\mathbf{P x}+\mathbf{M}(\mathbf{C})$ group; ruptered endothelial cells (arrows). H-E X100. 
Table I. The mean thicknesses of the corneal epithelium, stroma, descement membran and total cornea of all groups.

\begin{tabular}{|c|c|c|c|c|}
\hline Groups & Epithelium & Stroma & $\begin{array}{l}\text { Descement } \\
\text { membrane }\end{array}$ & Corneal thickness \\
\hline Sham & $87,85 \pm 16,9$ & $280,21 \pm 68,4$ & $21,53 \pm 4,67$ & $397,93 \pm 79,3$ \\
\hline $\mathbf{P x}$ & $99,58 \pm 29,7$ & $319,69 \pm 64,7$ & $24,05 \pm 7,26$ & $439,16 \pm 101,6$ \\
\hline Ovx & $144,55 \pm 17,2^{\mathrm{a}, \mathrm{b}}$ & $396,69 \pm 83,9^{a, b}$ & $24,89 \pm 2,62^{\mathrm{a}}$ & $562,79 \pm 97,6^{\mathrm{a}, \mathrm{b}}$ \\
\hline Ovx+Px & $100,12 \pm 15,5^{\mathrm{c}}$ & $393,61 \pm 40,2^{\mathrm{a}, \mathrm{b}}$ & $26,97 \pm 4,33^{\mathrm{a}}$ & $521,91 \pm 45,2^{\mathrm{a}}$ \\
\hline $\mathrm{Ovx}+\mathrm{Px}+\mathrm{M}$ & $109,77 \pm 12,4^{\mathrm{a}, \mathrm{c}}$ & $468,23 \pm 35,0^{a, b, f}$ & $24,13 \pm 4,80$ & $598,94 \pm 42,9^{\mathrm{a}, \mathrm{b}, \mathrm{f}}$ \\
\hline Ovx $+\mathbf{P x}+\mathrm{E}$ & $84,48 \pm 19,7^{\mathrm{d}, \mathrm{e}}$ & $343,74 \pm 62,4^{\mathrm{e}}$ & $19,01 \pm 2,48^{\mathrm{d}, \mathrm{e}, \mathrm{g}}$ & $455,62 \pm 56,1^{\mathrm{c}, \mathrm{g}, \mathrm{e}}$ \\
\hline $\mathrm{Ov} x+\mathrm{Px}+\mathrm{EM}$ & $87,89 \pm 20,6^{\mathrm{d}, \mathrm{e}}$ & $\begin{array}{c}385,96 \pm \\
46,0^{\mathrm{a}, \mathrm{b}, \mathrm{e}}\end{array}$ & $21,88 \pm 2,15^{\mathrm{g}}$ & $513,68 \pm 54,9^{\mathrm{a}, \mathrm{e}}$ \\
\hline
\end{tabular}

${ }^{a}$ Significant increase $(\mathrm{P}<0.05)$, vs. Sham group, ${ }^{\mathrm{b}}$ Significant increase $(\mathrm{P}<0.05)$, vs. Px

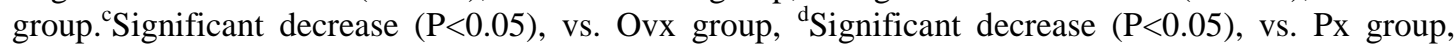
${ }^{\mathrm{e}}$ Significant decrease $(\mathrm{P}<0.05)$, vs. Ovx $+\mathrm{Px}+\mathrm{M}$ group, ${ }^{\mathrm{f}}$ Significant increase $(\mathrm{P}<0.05)$, vs. Ovx $+\mathrm{Px}$ group. ${ }^{\text {g}}$ Significant decrease $(\mathrm{P}<0.05)$, vs. Ovx $+\mathrm{Px}$ group

\section{Discussion}

The eye is a highly sensitive organ that is known to be impacted by changes in physiological conditions of the body (eg, menopause, pregnancy, menstrual cycle). Menopause has been reported to impact the structural integrity of cornea through changes in its curvature and thickness (Aydin et al., 2007, Affinito et al., 2003). Numerous studies have indicated that sex steroids (i.e. androgens, estrogens and progestins) may modulate the structural characteristics, functional attributes and/or pathological features of ocular tissues, and that these hormone actions may account for many of the gender-related differences in the eye. However, despite this endocrine influence, very little information exists concerning the precise mechanism(s) underlying sex steroid effects (Wickham et al., 2000). Animal models have been used for investigation of pathogenic mechanisms of diseases due to menopause as well as for treatment modalities. The experimental model for cornea disease induced by ovariectomy and pinealectomy in female rats is also commonly used and is very useful for evaluation of problems related to cornea damage in postmenopausal women. The present study was to expose rats to one aspect of the ageing process via surgical pinealectomy (Px) and ovariectomy (Ovx) and evaluate the effect of melatonin and estrogen replacement against Ovx and Px rat model through the identification of histochemical alterations of the cornea tissue.

Sex steroid hormones, namely estrogen, progesterone, and testosterone, are produced by ovaries in females and testes in males. Although they circulate through blood, their effects rely on the receptors present in specific tissues and organs. These receptors are widely expressed in different ocular tissues, including the cornea. Corneal tissues express estrogen receptors types $\alpha$ and $\beta$ progesterone receptors, and androgen receptors (Gupta et al., 2005).

Corneal thickness varies throughout development to adulthood and from person to person (Mishima et al., 86). A major contributor to corneal thickness has been associated with altered hormone levels with varying effects on corneal thickness occurring during pregnancy (Weinreb et al., 88) and aging (Niederer et al., 2007). Hormones mediate changes in cell function via binding to their respective receptors with both the androgen receptor (Rocha, et al., 2000, Suzuki et al., 2001). and estrogen receptor (Wickham et al., 2000) being expressed within the human cornea suggesting that hormones may influence corneal function directly. Based on the expression pattern of $\alpha$ and $\beta$ estrogen receptors in corneal cells, it has been postulated that estrogen is supplied through tears and aqueous humor at concentrations that are approximately half the concentrations found in plasma (Tachibana et al., 2000). Hormone replacement therapies have been associated with a decreased incidence of ocular diseases, such as glaucoma (Sator et al., 97) AMD (Smith et al., 97) and cataract (Cumming et al., 97, Klein et al., 94) further suggesting a central role for estrogens in ocular physiology. The proposed mode of action of these steroidal hormones is via the regulation of gene expression in the nucleus, leading to changes in the concentration of ECM proteins, which are critical to the maintenance of corneal integrity (Khaled,et al., 2017) 
In this study, we found that pinealectomy and ovariectomy caused an increase in the thickness of the epithelium, stroma, descement membrane and total cornea. Also in Px, Ovx and Px+Ovx groups, the stroma was highly edematous. Wide detachment in the stroma were observed. In order that, these histopathological changes were improved significantly by estrogen treatment with compare to melatonin treatment. It is plausible that estrogen may be responsible for weakening the cornea via the stimulation of matrix metalloproteinases and the release of prostaglandins, causing activation of proteolytic enzymes for collagen and reduction in corneal-stiffness (Spoerl et al., 2007).

In conclusions, we demonstrated that estrogen administration was more effective than melatonin against corneal disorders in ovariectomized (Ovx) and pinealectomized (Px) rats.

Conflict of interest: There is no conflict of interest among the authors.

Funding: No funding has been received from any source.

\section{References}

Affinito P, Di Spiezio Sardo A, Di Carlo C, Sammartino A, Tommaselli GA, vet al. Effects of hormone replacement therapy on ocular function in postmenopause. Menopause. 2003;10:482487.

Aydin E, Demir HD, Demirturk F, Çalışkan AC, Aytan H, Erkorkmaz U. Corneal topographic changes in premenopausal and postmenopausal women. BMC Ophthalmol. 2007; 7:9. 7.

Cumming RG, Mitchell P. Hormone replacement therapy, reproductive factors, and cataract: the Blue Mountains Eye Study. Am J Epidemiol. 1997; 145:242-249.

Esposito E, Cuzzocrea Antiinflammatory activity of melatonin in central nervous system. S. Curr Neuropharmacol. 2010;8(3):228-42. doi: 10.2174/157015910792246155.

Evans RM. The steroid and thyroid hormone receptor superfamily. Science. 1988;240:889-895.

Giuffré G, Di Rosa L, Fiorino F, Bubella D, Lodato G. Variations in central corneal thickness during the menstrual cycle in women. Cornea. 2007;26(2):144-146.

Gupta P.D Kaid JoharSr.Nagpal K., Vasavada A.R. Sex Hormone Receptors in the Human Eye Surv Ophthalmol 2005; 50 (3) 274-84.

Hoffman RA, Reiter RJ. Rapid pinealectomy in hamsters and othersmall rodents. Anat Rec 1965; 153: $159-121$.

Khaled,ML Helwa I, Drewry, M Seremwe, M Estes A, Liu Y. Molecular and Histopathological Changes Associated with Keratoconus Biomed Res Int. 2017; 2017: 7803029.

King WJ, Greene GL. Monoclonal antibodies localize oestrogen receptor in the nuclei of target cells. Nature. 1994;307:745-747.

Klein BE, Klein R, Ritter LL. Is there evidence of an estrogen effect on age-related lens opacities? The Beaver Dam Eye Study. Arch Ophthalmol. 1994;112:85-91.

Kumar V, Green S, Stack G, Berry M, Jin JR, Chambon P. Functional domains of the human estrogen receptor. Cell. 1987;51:941-951.

Mediavilla MD, E J Sanchez-Barcelo, D X Tan, L Manchester, R J Reiter Basic Mechanisms Involved in the Anti-Cancer Effects of Melatonin Curr Med Chem ACTiONS 2010;17(36):446281. doi: 10.2174/092986710794183015

Mishima, S. Corneal thickness - a review. Surv Ophthalmol 1986; 13:57-96. 
Mittanamalli S Sridhar. Anatomy of cornea and ocular surfaceIndian J Ophthalmol. 2018; 66(2): 190-194. doi: 10.4103/ijo.IJO_646_17

Niederer, R. L., Perumal, D., Sherwin, T. \& McGhee, C. N. Age-related differences in the normal human cornea: a laser scanning in vivo confocal microscopy study. The British journal of ophthalmology 2007; 91, 1165-1169, doi: 10.1136/bjo.2006.112656 ().

Reiter R.J. Neuroendocrine effects of light. Int. J. Biometeorol. 1991;35(3):169-175.

Reiter R.J., Tan D.X., Korkmaz A., Rosales-Corral S.A. Melatonin and stable circadian rhythms optimize maternal, placental and fetal physiology. Hum. Reprod. Update. 2014;20(2):293-307.

Rocha, E. Wickham L, da Silveira L. A, Krenzer K., Yu F., Toda I. et al. D.Identification of androgen receptor protein and 5alpha-reductase mRNA in human ocular tissues. The British journal of ophthalmology 2000; 84: 76-84.

Samples JR, Krause G, Lewy AJ. Effect of melatonin on intraocular pressure. Curr Eye Res. 1988;7:649-653.

Sator MO, Joura EA, Frigo P, Kurz C, Metka M, Hommer A, et al. Hormone replacement therapy and intraocular pressure. Maturitas. 1997;28:55-58.

Smith W, Mitchell P, Wang JJ. Gender, oestrogen, hormone replacement and age-related macular degeneration: results from the Blue Mountains Eye Study. Aust N Z J Ophthalmol. 1997;25:1315 .

Spoerl E., Zubaty V., Raiskup-Wolf F., Pillunat L. E. Oestrogen-induced changes in biomechanics in the cornea as a possible reason for keratectasia. The British Journal of Ophthalmology. 2007;91(11):1547-1550. doi: 10.1136/bjo.2007.124388.

Suzuki T, Kinoshita Y, Tachibana M, Matsushima Y, Kobayashi Y, Adachi W, et al. Expression of sex steroid hormone receptors in human cornea. Curr Eye Res 2001; 22:28-33.

Tachibana M, Kasukabe T, Kobayashi Y, Suzuki T, Kinoshita S, Matsushima Y. Expression of estrogen receptor alpha and beta in the mouse cornea. Invest Ophthalmol Vis Sci. 2000;41:668670 .

Waynfort HB, Flecknell PA. Ovariectomy. In: Experimental and Surgical Technique in the Rat. London: Academic Press, 1992: 276-278.

Weinreb, R. N., Lu A. \& Beeson, C. Maternal corneal thickness during pregnancy. American journal of ophthalmology 1988; 105: 258-260.

Wickham LA, Gao J, Toda I, Rocha EM, Ono M, Sullivan DA. Identification of androgen, estrogen and progesterone receptor mRNAs in the eye. Acta Ophthalmol Scand 2000; 78:146-53.

Wiechmann AF, Hollaway LR, Rada JA. Melatonin receptor expression in Xenopus laevis surface corneal epithelium: diurnal rhythm of lateral membrane localization. Mol Vis. 2009; 17:(15) 2384-403. 